\title{
Metacognitive Strategy in Teaching Reading to Primary Students
}

\author{
Diana Tandean \\ diana.tandean@gmail.com \\ Primary School \\ Mawar Sharon Christian Scool \\ Surabaya, Indonesia
}

\begin{abstract}
Article History
Received: $\quad 01 / 23 / 2020$

Reviewed: $\quad 06 / 10 / 2020$

Accepted: $\quad$ 09/30/2020
\end{abstract}

Keywords:

Metacognitive strategies, reading comprehension, young learners

DOI:

https://doi.org/10.33508/bw.v8i2.2320

\begin{abstract}
In raising young learners' awareness of their own reading comprehension, educators can implement metacognitive strategy as one of the solutions. Therefore this study aims to know the effectiveness of metacognitive strategy in teaching reading to primary students. The grand theory employed in this study is the six sequential reading strategies proposed by Brown, Palinscar and Armbruster's (1984). The research method is pre-experimental study with three groups of third graders as the subjects. The researcher designed a reading assignment for each treatment, as well as a reading test as the research instrument. The pre-test and post-test data was analyzed using paired t-test. The data shows a significant difference between pre-test and post-test scores among all three groups.
\end{abstract}

\section{Introduction}

Throughout the years Indonesian government has strived to improve the education quality in terms of cognitive, affective and psychomotor aspects. The latest development would be K-13 curriculum which employs thematic learning which enables more holistic strategies of learning. What is lacking from the current education system is the ability of learners to regulate their own learning. If we look at the constraints of the curriculum, there is little to no time provided for doing metacognitive reflection. All of the lessons time is allocated to teach and learn the materials. It is likely going to be a challenge for teachers to implement metacognitive strategies when the curriculum is not flexible enough for it.
Most schools still heavily employ teacher centered strategies where the teachers will guide the students to conduct their learning without necessarily telling the reason why should they learn about it, thus paralyzing the students' potential to regulate their own study. This is when metacognitive strategies become crucial in triggering students' thinking skill and deepening their level of their thinking. Students should not passively receive information from the teachers but they are supposed to make use of the information according to their needs and monitor their progress. This kind of process should start as early as possible since it requires a relatively long time to master. That is why the researcher chose primary students 
as the subject of the research in hope that metacognitive strategies will be imple-

Reading skill in this matter can be quite challenging for EFL students to master. Many researches have shown that most EFL learners utilized few to no strategies in handling academic reading demands. The common problems are the lack of knowledge of the learner's own thinking process (Maasum \& Maarof, 2012) and vocabularies comprehension. Teachers, on the other side, tend to directly teach the reading passage without activation of schemata. Metacognitive strategy is one of the answers to develop reading skill as it helps students to make connection between past knowledge and new information from the reading passage (Collins \& Smith, 2008). mented since early years of education.

Metacognitive strategies should be introduced since primary level so that students will train themselves to regulate their knowledge since early childhood phase. They also need to be able to monitor their own progress and make concious effort to deepen reading comprehension, thus making them "active and constructively responsive readers" (Sheorey and Mokhtari, 2001). Moreover, many studies have shown that the success of reading strategy was dependent on the way the strategy is employed, whether metacognitively or not (Jimenez et al., 1996). That means, knowing reading strategies is not enough. Students also need to be able to employ them metacognitively. In fact, poor readers might know reading strategies cognitively but unable to implement them metacognitively.

\section{Literature Review}

\section{Reading}

Reading is no longer a quiet, private and rather passive model. The definition of reading has evolved towards a more dynamic interaction between readers' background knowledge, information provided by the written language and the context of the reading situation in order to form meaning, as what Dutcher (1990) suggested. So reading is a complex and multidimensional process which requires vocabularies knowledge, phonological knowledge, content related knowledge and reading strategies.

\section{Metacognition}

Metacognition consists of two words, which are "meta" and "cognition". According to Shirley Larkin (2010), Meta refers to "going beyond" something or moving to the next level, while cognition refers to our faculty of knowing or thinking. So, metacognition is basically the deeper level of cognition where one is aware of the ongoing thinking process and has the ability

of to reflect upon it. This is the second level of thinking, referred as "thinking about thinking" or "learning to learn". The purpose of implementing metacognition is so that learners will be able to make wise and thoughtful life decisions as well as to comprehend and learn better in formal educational settings. (Flavel 1979, p.910).

\section{Components of Metacognition}

There are two basic components of metacognition initiated by Brown (1978). They are knowledge of cognition and regulation of cognition. Knowledge of cognition is how much the learners know about their memories and the way they learn. Knowledge of cognition can be divided into three distinct areas which are:

1. Declarative knowledge. Declarative knowledge is the knowledge about description or attributes of the matter in hand. 
2. Conditional knowledge. Conditional knowledge refers to knowledge about conditions.

3. Necessary to carry out a certain activity. Regulation of cognition is what the learners do with their knowledge of cognition. Regulation of cognition also contains several subcomponents such as planning, se-

\section{Principles of Metacognition}

The process happening between components of metacognition can be understood through the principles of metacognition. As described in the model made by Thomas $\mathrm{O}$. Nelson and Louis Narens (1990) there are three abstract principles of metacognition. This clearly describes the correlation between cognition and metacognition, as well

Meta-level is one's mental perception of the object being learned. Meta-level and object-level are simultaneously affecting one another throughout the thinking process. Third, there are two dominance relations,
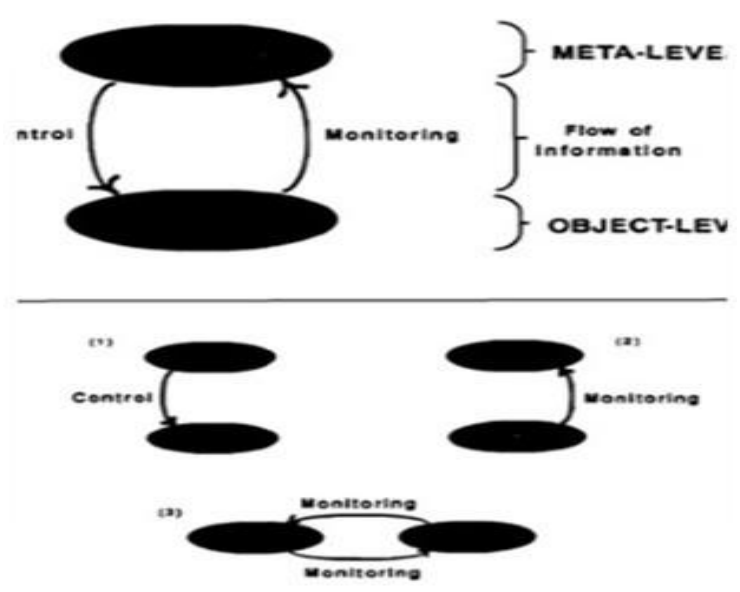

Fig.1 Nelson \& Naren's Principle of metacognition

called "control" and "monitoring," which are defined in terms of the direction of the flow of information between the meta-level and the object-level.

Control is the ability of meta-level to modify the object-level, or in other words, it is the regulation of cognition at work, as as the ongoing process between them. First, there are two interrelated levels in our mind, which are meta-level and object-level. Second, the meta-level contains a dynamic model (e.g., a mental stimulation) of the object-level.

mentioned above. Monitoring is the process of providing information by the object-level to give feedback to the meta-level as introspection material. This process is optimizing the use of knowledge of cognition. Both levels have to be activated in one's mind, so that the controlling and monitoring processes might happen.

Meta-level is one's mental perception of the object being learned. Meta-level and object-level are simultaneously affecting one another throughout the thinking process. Third, there are two dominance relations, called "control" and "monitoring," which is defined in terms of the direction of the flow of information between the meta-level and the object-level.

Control is the ability of meta-level to modify the object-level, or in other words, it is the regulation of cognition at work, as mentioned above. Monitoring is the process of providing information by the object-level to give feedback to the meta-level as introspection material. This process is optimizing the use of knowledge of cognition. Both levels have to be activated in one's mind, so that 
the controlling and monitoring processes might happen.

Based on the principles of meta-cognition, in order to implement metacognitive strategies in academic context, one has to be able to modify his cognitive knowledge to produce an output which meets the expected result. For example, a grade 2 student is trying to write about his holiday last summer in an English reading lesson. Given his limited vocabularies and literacy level, when he tries to describe something he has never seen before, he has to find a way to describe the object by its appearance without knowing the object's name. He has to activate his meta level in order to find a strategy in overcoming his problem. He then will revisit his existing knowledge of vocabulary and construct the words that he knows to describe the object. Afterwards, a student with activated metacognition will monitor the result of his work by examining his reading, whether it is correct according to his existing knowledge or not. The strategy used to tackle the problem is a metacognitive strategy previously stored in one's mind, possibly due to previous problems. Kostons \& Van der Werf (2015) demonstrated the positive correlation between metacognition and learning by comparing the effects of prior topic knowledge and prior metacognitive knowledge on performance in a task. Therefore, we can possibly develop metacognitive strategies in one's mind by giving constant exposure to various problems. However, metacognitive development also depends on many other factors such as self-motivation, self-perception and external supports.

\section{Metacognition in Primary students}

Metacognitive development is available to all periods of developmental stages. It does not necessarily develop in line with the orders of thinking skill. Adults are not always better in exercising metacognitive strategies compared to young children. According to Piaget, naturally, most children will develop the skill to think from other people's point of view which is called "de-centering", where the child is no longer only focused on herself but can see things from another perspective (Piaget \& Inhelder, 1969). This is the birthing point of metacognition in young children.

According to Shirley Larkin (2010) there are pre-cursor theories which can be used to assess children's metacognitive development, which are meta-memory and meta knowing. Meta-memory involves knowledge of one's own memory, how it works, what factors may influence it, what strategies may be useful in helping us to remember things as well as ongoing control and monitoring of our memory (Flavell, 1971; Flavell\& Wellman,1977) This means children are aware of what they know, how they store memories and how they can integrate new memories to the existing one. In order to assess this particular capability, researchers can conduct series of tests such as false belief test, memory tests, etc. Interview is also a crucial instrument to give a hint of a child's thinking process.

While meta-knowing is defined as awareness and understanding of one's own cognitive functions and those of others. (Deanna Kuhn 2000). Children with metaknowledge are aware of how well they know about something and how much their friends know compared to their knowledge. In classroom context, usually children will be able to identify who are the smart ones and who are the less knowledgeable. Meta - knowing are differentiated into two stages, "knowing that" which is knowing something as a matter of fact and "knowing how" which relates to 
meta-strategies. Meta-memory and metaknowing develop during early childhood, while meta-strategies develop much later.

It is crucial for children not just to be aware of how much they know, but also how can they fill in the gap by conducting some strategies. Otherwise, children will start to label themselves and stop developing their thinking skill beyond the arbitrary limit they create for themselves. In order to assess the development of children's meta-strategies, several tests can be held, such as the marshmallow test. Delayed gratification may lead children to develop meta-strategies in order to get better result.

\section{Method}

\section{Research Design}

This research employed preexperimental design, three groups with pretest and post -test. The English teacher taught all subjects in three different groups. The result of the post test was compared to the pretest in order to show the significance of metacognitive reading strategy in enhancing students' comprehension.

\section{Research Setting}

The research was conducted in a bilingual school in Surabaya. The school employs both Cambridge and national curriculum. The research treatment was held for 4 weeks, in August 2019. The reasearch treatment was conducted once a week, started with pretest in the first week, ended with postest in the sixth week.

\section{Subject}

Armbruster's (1984) six strategies of reading which are (1) understanding the purpose of the text, (2) activate background knowledge, (3) allocate attention to main ideas, (4) monitor comprehension, (5) critical evaluation and (6) drawing inferences. The teacher guided the subjects from the first to the last step throughout the treatment, since the subjects were not yet familiar with the treatment.

The ultimate advantage of implementing metacognitive strategies in the long run is transference from other regulation to selfregulation, according to Brown (1987) \& Vygotsky (1978). This can only happen
The subjects of this research are sixty six third graders of ESL learners in a bilingual school. There are four classes, each of them has twenty four students. One class served as the pilot class, the other three as the subjects. The researcher used three classes to ensure the consistency of the result in all classes, since the number of subjects in each class in relatively low.

Most subjects are from middle up class families, nine to ten years old. They prefer to use English in their daily conversation at school and Indonesian, their mother tongue, at home. All subjects have learned English since they were in the pre-school.

\section{Research Treatment}

All the subjects in the group received the same treatment. The treatment is designed based on Brown, Palinscar and

when the teachers or parents gradually decrease their support in order to let the children face their problems and find their own strategies to overcome. According to Paris and Winograd (1990) there are three aspects of self-regulated learning: awareness of thinking, use of strategies and sustained motivation. Awareness of thinking and use of strategies pretty much sum up metacognition in general, while sustained motivation relates to self-perception and the reason why children must achieve something.

\section{Metacognitive Teaching Strategies}

Traditionally, assessments employ more convergent questions than divergent ones. In order to boost students' metacognition, more 
divergent questions, especially reflective and evaluative ones are highly recommended (Haidar \& Al Naqabi, 2008). The number of both convergent and divergent questions should be balanced in order to develop both students' metacognition and cognition. As stated before, metacognition is a rather long internalization process; therefore it requires constant and repetitive practice, especially for primary students. Scharlach (2008) suggests teaching metacognitive strategies, such as making predictions, visualizing, and summarizing all across subjects repetitively.

In terms of teaching metacognitive strategies, Kistner et al., (2010) suggested teachers to do it more deliberately and explicitly. This will boost more strategy usage among the students and their awareness about the strategies they are using. Not just strategies, teachers also should post thoughtful questions to help the students verbalize their thoughts and think out loud. Guiding the students to find the right strategy for each problem is also important to develop their metacognition.

\section{Metacognitive Strategies in Teaching Reading}

As stated above, there are three types of cognitive knowledge according to Brown (1978), they are Declarative knowledge, Procedural knowledge and Conditional knowledge. Jacob \& Paris (1987) define Declarative knowledge in terms of reading as propositional information that readers have in doing a certain task, such as 'knowing' that conducting post-reading strategy will help readers to reflect upon their reading ability. While Procedural knowledge in this context means how one actually carries out the strategy he / she knows. As for Conditional knowledge, it talks about the awareness about factors that might affect one's success in learning, such as knowing what conditions should be achieved in order to implement post reading strategy. These are the three types of knowledge that teachers need to share to their students in teaching reading.

In order to teach the three types of knowledge, teachers can implement six startegies proposed by Brown, Palinscar and Armbruster's (1984) to enhance student's comprehension of text: (1) understanding the purpose of reading, (2) activating relevant background knowledge, (3) allocating attention to main ideas, (4) critically evaluating, (5) monitoring comprehension, and (6) drawing inferences. These six metacognitive strategies of teaching reading are what the researcher going to implement in this study

Understanding the purpose of reading. Before starting to read it is important for readers to know what to expect from their reading. It will help them to set the goals of the reading activity and eventually achieve them. Therefore in this first step, teachers must give understanding to their students what kind of text they are going to read, what will they learn from the text and what strategies can they use to achieve the goal.

1. Activating background knowledge. Activating relevant background knowledge is a metacognitive activity where students connect their previous knowledge to the current knowledge they are learning. This process happens in the meta-level of one's mind, as it relates the student's perception about what is being read and the reading itself. Students who are able to connect their background knowledge to the text tend to comprehend the text better than those who do not relate the text to their background knowledge or those who do 
not have sufficient background knowledge related to the text.

2. Allocating attention to main ideas. Identifying the main idea of each paragraph will help students to eventually determine the main idea of the whole text. Especially for students who experience difficulties in finding the main ideas, doing it in smaller chunks will help them to draw conclusion about the big idea more easily.

3. Critical evaluation. Gaining comprehension about the main ideas is not enough. Students need to go further by critically evaluating the content of their reading. They need to think of critical questions like, "What is the author trying to say? What is important for readers to understand? Do I agree with the writer's argument?", etc. These critical questions will help students to digest what they have read and make the knowledge their own.

4. Monitoring comprehension. Students need to be aware whether they truly comprehend every part of the text. They need to notice if there is any confusing part or something new that they have never heard of before. Harvey and Goudvis (2007) suggested "Stop, Think and React" strategy to help students monitor their comprehension. In this context, the best response to reading is to simply talk about it. That is why studentto-student conversation during reading process is greatly encouraged. Another way students can do to respond to the text is to write comments or draw pictures that express what they have in mind about the text. Drawing is especially suitable for younger children or children with problems in expressing their thoughts into words. Teachers should give time for students to give response to the text as this ensures better reading comprehension.

5. Drawing inferences. By the end of reading process, students need to come to a conclusion of what they have just read. Not only that, they also need to identify what they have learned from the text and incorporate the new knowledge with the existing one. This is a metacognitive process where the meta-level is modified by the object-level of one's mind. When new knowledge is stored in one's memory, it will become the schema for the upcoming information. Drawing appropriate conclusion becomes a crucial skill students must possess so that they can expand their knowledge and have wide range of resources as their schemata.

\section{Previous Studies}

Zhussupova \& Kazbekova (2016) did a small-scale quasi experimental study which examined the effectiveness of metacognitive strategies to reading comprehension. The study was done in the frame of a metacognitive pedagogical model that included 3 stages: a) preparation, b) active work, c) analysis. The setting of the study was at the Eurasian National University with 2nd year students who were taught English as a foreign language for 15 weeks. As a result of this research, the authors formulated a teacher's manual called "GUIDE to using metacognitive strategies in teaching reading comprehension. The study also provided a sample of lesson plan based on the teacher's manual. This research shows that metacognitive strategies significantly improved young learners' reading comprehension.

On the other hand, Nash-Ditzel (2010) conducted a case study which explores the impact of metacognitive reading strategies. The subjects (five college students) joined developmental courses to self-regulate while 
reading. There were six reading instructions used in this study, adapted from the research of Pearson and Gallagher's (1983). This study showed the positive impact of metacognitive reading strategies on college students' ability to self-regulate while reading. At the beginning of the study, some students' comments about the text were out of context and they were not aware of it. Later on, after repeated treatment, the subjects could stay on track better. The six reading instructions are very similar to the six steps implemented in the current study.The instructions, however, will be simplified and scaffolded to meet the needs of primary students.

In order to know the use of metacognitive reading strategies in children with learning disabilities, Nicolielo-Carrilho \& Hage (2017) conducted an experimental study on 30 children, aged 8 to 12 years, of both gen-

\section{Table 1}

\section{Research Treatment Table}

\section{Pre-Reading, Whilst-Reading and Post-Reading Activities}

\section{Pre-reading}

1. understanding the purpose of the text. The teacher told the student the purpose of reading the text, such as to gain information from the text or to know the desription of something.

2. activate background knowledge. The teacher asked the students to skim the text (read only the first sentence of each paragraph) and asked the students to predict what is the text about. The teacher gave triggering questions related to the text.

\section{Whilst-reading}

1. allocate attention to main ideas. After giving triggering questions, teacher and the students read aloud in turns. After reading every one paragraph, teacher gave a short pause and asked the student to seek for the main idea of the paragraph.

2. monitoring comprehension. The teacher asked the students to respond to each paragraph they have read. They could respond by writing parts of the text they do not understand. They could also give comments or draw something about what the text reminds them of.

\section{Post-reading}

1. Critical evaluation. The teacher asked the students higher order thinking questions related to the text, such as "What is the author trying to say?, What is important for the readers to understand?"

2. Drawing inferences. After critical evaluation, students were required to draw conclusion of what the text is all about. They had to write their conclusion on the conclusion box. 
In order to facilitate Monitoring the Comprehension process in the treatment, the researcher has designed a reading assignment completed with a comment column and comprehension box, as shown in the figure 2 below. Naturally, active responses are given orally and spontaneously by reading participants. However, since this research was conducted in a classroom context, so comment column and conclusion box are necessary to ensure all participants' active response to each paragraph. They can write their comment or draw a picture that they think relates to the paragraph they are reading. Each assignment will have a different title every week.

The enemies decided to come from different directions and make a surprise attack on Jerusalem. When the Jews heard about the plan, they were frightened. But Nehemiah said: 'Don't be afraid. God is with us.' He posted guards to protect the workers, and the enemies were not able to attack.

In just 52 days, the walls and the gates were completed. Nehemiah brought all the Levites to Jerusalem for the inauguration. He organized them into two groups of singers. They went up on the wall by the stairs at the Fountain Gate and then marched in opposite directions around the city. They played trumpets, cymbals, and harps and sang to God. Ezra went with one group, and Nehemiah with the other, until they met up at the temple. All the people-men, women, and children-offered sacrifices to God and celebrated. The sound of their happy voices could be heard far away.

"No weapon formed against you will have any success." - Isaiah $\underline{54: 17}$

What have you learned from the story? Please describe in the box below using at least 5 sentences.

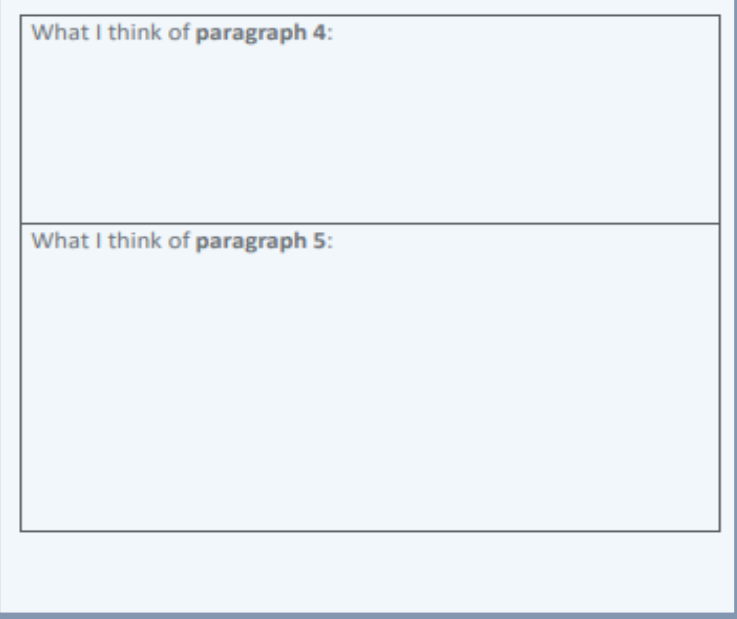

Fig 2. Comment column (in blue) and Conclusion box (in red)

Table 2

\section{Research Timeline Table}

\begin{tabular}{|l|c|}
\hline Week & Research Treatment \\
\hline Week 1 & Pre-Test : Reading Comprehension Test \\
\hline Week 2 & Treatment 1 \\
\hline Week 3 & Treatment 2 \\
\hline Week 4 & Treatment 3 \\
\hline Week 5 & Treatment 4 \\
\hline Week 6 & Post Test: Reading Comprehension Test \\
\hline
\end{tabular}

\section{Data Collection Procedures}

First of all, the researcher collected the previous English mean score of all subjects. The data was taken from the previous

students' ledgers. These mean scores were important for researchers to determine whether all the participant have relatively 
equal English proficiency or not. After that, the researcher also collected the data through pretest and posttest. The purpose of conducting the pre-test is to know the paticipants' prior reading skill before the research is conducted. The pre-test and posttest was designed by the researcher in order to test the subjects reading comprehension in standardized tests usage. The research instrument consists of multiple choice questions out of four reading passages. Most questions were designed in higher order thinking fashion which requires the subjects to fully comprehend the text before they can answer correctly. All of the answers were As for the research treatment, subjects were given reading assignments in order to monitor their reading comprehension and the reading strategy used by the subjects. and to minimize cultural gap often occuring not explicitly stated in the reading passages.

\section{Technique of Data Analysis}

First, the researcher analyzed the mean score of previous English score from each class using One Way ANOVA Homogenity Test in order to find if there is any significant difference in terms of their English proficiency between four classes. If there is no significant difference, one class will be randomly chosen as the pilot class. Afterwards, data will be taken from the three other classes.

After all scores were compiled by the researcher, the data was analyzed and compared using ANOVA paired t-test. The researcher tried to find whether there is a significant difference between pre-test result and post-test result. This would help the researcher to see if there is any growth in subjects' ability to implement the metacognitive strategy in their reading activities.

\section{Findings}

Before implementing the research treatment, there were several steps of statistical analysis that the researcher took. First, the rearcher seeks to know if there is any significant difference between the four groups of subjects, especially in terms of their English skill. So the researcher compiled the English ledger from the previous grade. After collecting the previous ledger, the researcher did a homogeinity test using One Way ANOVA to analyze whether there is any significant difference between each group .The result shows that the value of Sig. $0.758>0.005$ which means that there is no significant difference between groups. Since all groups have relatively equal English skill, that means the research can be implemented among the current subjects.

The next step the researcher took was testing the validity of each item in the research instrument. The researcher randomly chose the fourth group to be treated as the pilot test group. The fourth group was given a reading comprehension test that consists of 25 multiple choice questions. The researcher then analyzed the result using Pearson formula in Microsoft Excel. The result shows that out of 25 items, 20 items show higher t-count value than the t-table $(1,7341)$. That means only 20 items are valid to be used as the research instrument. Therefore, the researcher eliminated the 5 invalid items and used the remaining 20 items as the pretest and posttest material.

The researcher then did a reliability test over the remaining 20 items. The reliability of research instrument was tested using Cronbach's Alpha reliability test. The Reliability Statistics table shows that Cronbach's alpha value $0.864>0.6$ which means the test is reliable. Item-Total Statistics table further shows the reliability of

BEYOND WORDS Vol. 8, No. 2, November 2020 Graduate School, Widya Mandala Catholic University Surabaya 
the instrument if any item is deleted. The last column of the table shows relatively constant reliability throughout the test if any item is deleted from the instrument. Therefore it is safe to say that the research instrument is valid and reliable, thus eligible to be used in this research.

Eventually, the pre-test, treatment and post test are conducted among the remaining groups (group 1-3). Some subjects, however, did not complete both pre-test and post-test due to their unavailabilty, so the following analysis will eliminate subjects who did not manage to do both tests. The remaining subjects are: Group $1=22$, Group $2=23$ and Group 3= 21 .

Before the researcher can analyze the data further, the researcher needs to analyze whether the data distribution of the finding is normal. The researcher used normality test: One Sample Kolmogorov-Smirnov Test. The analysis result shows that the test distribution is normal, therefore the researcher continued the analysis using paired t-test to find whether metacognitive strategies used in this research significantly improved subjects' reading comprehension. The analysis result is shown in the Paired Samples Statistics table below.

Table 3

\section{Paired Samples Statistics Table}

\section{Paired Samples Statistics}

\begin{tabular}{ll|l|l|r|r} 
& & & & & \multicolumn{2}{c}{$\begin{array}{c}\text { Std. Error } \\
\text { Mean }\end{array}$} \\
\hline Pair 1 & Group 1 Pretest & 53.41 & 22 & 18.086 & 3.856 \\
\cline { 2 - 7 } & Group 1 Posttest & 67.50 & 22 & 19.071 & 4.066 \\
\hline Pair 2 & Group 2 Pretest & 45.22 & 23 & 17.868 & 3.726 \\
\cline { 2 - 6 } & Group 2 Posttest & 63.04 & 23 & 19.113 & 3.985 \\
\hline Pair 3 & Group 3 Pretest & 52.62 & 21 & 18.816 & 4.106 \\
\cline { 2 - 7 } & Group 3 Posttest & 61.90 & 21 & 20.154 & 4.398 \\
\hline
\end{tabular}

\section{Table 4}

\section{Paired Samples Statistics Table}

Paired Samples Correlations

\begin{tabular}{ll|r|r|r} 
& N & Correlation & Sig. \\
\hline Pair 1 & $\begin{array}{l}\text { Group 1 Pretest \& Group } \\
\text { 1 Posttest }\end{array}$ & 22 & .481 & .023 \\
\hline Pair 2 & $\begin{array}{l}\text { Group 2 Pretest \& Group } \\
\text { 2 Posttest }\end{array}$ & 23 & .707 & .000 \\
\hline Pair 3 & $\begin{array}{l}\text { Group 3 Pretest \& Group } \\
\text { 3Posttest }\end{array}$ & 21 & .794 & .000 \\
\hline
\end{tabular}




\section{Table 5}

\section{Paired Samples Test Table}

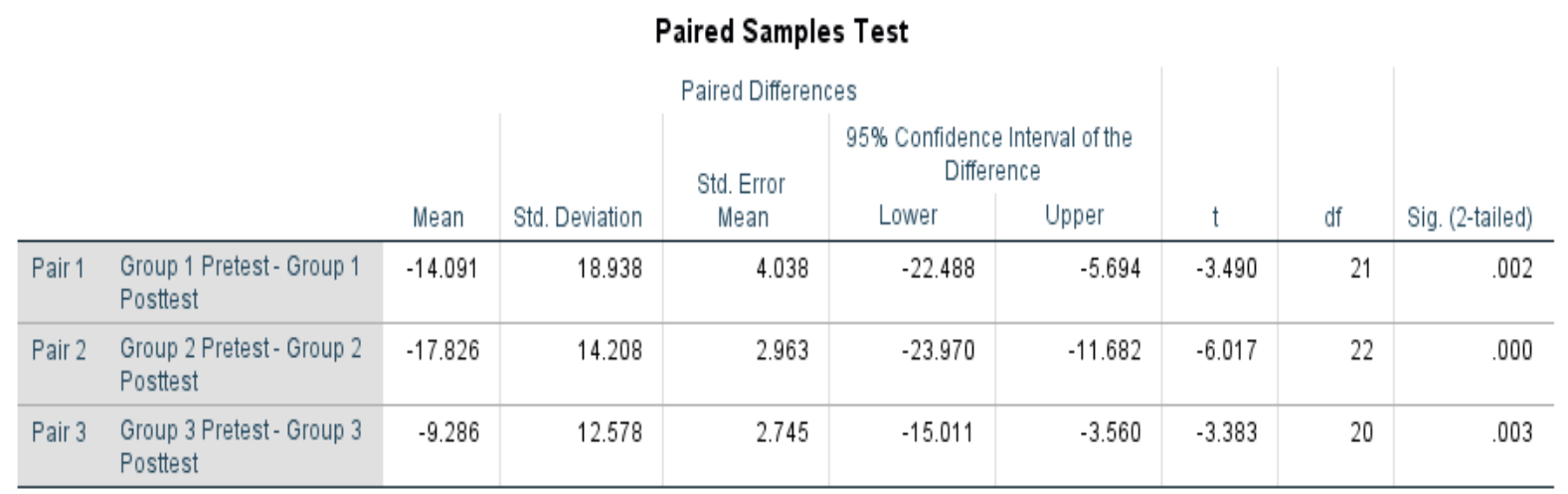

The Sig (2-tailed) column shows that each group's significant value is less than 0.005; Pair 1: $0.002<\alpha=0.05$, Pair 2: $0.00<$ $\alpha=0.05$, Pair 3: $0.003<\alpha=0.05$. While the $\mathrm{t}$ value of each pair is bigger than t- table value; Pair 1: 3.490> 1.717, Pair 2: 6.017>1.714, Pair 3: 3.383>1.721. This result shows that the usage of metacognitive strategy in this research significantly improved the subjects' reading comprehension. So the research hypothesis is accepted (Ha): There is a significant difference between the reading achievement of grade three students before and after treatment, is accepted. While the null hypothesis (Ho): There is no significant difference between the reading achievement of grade three students before and after treatment, is rejected. However, it is worthy to note that the standard deviation value is relatively high which means there is a considerable gap between the high achievers and the low achievers in each group.

During the weeks of treatment, the researcher also found out that most subjects have the tendency to draw pictures in the comment box rather than expressing their thoughts in words. Even when they comprehended the text, most of them still found it difficult to create a response to the text, probably it was because they are not used to giving active responses to reading passages. Another possible reason is the subjects' limited vocabularies in expressing their thoughts. Some subjects find it hard to express their thoughts simply because they do not have the words to express them. Therefore, the teacher had to give prompting questions to help the subjects in creating comments throughout the treatment.

\section{Discussions}

Metacognitive strategy implemented in this research is still not very common among educators in Surabaya, Indonesia. In fact most teachers in the school where this research was conducted, are not familiar with the term "metacognitive". So the treatment carried out in this research was relatively new to the subjects.
Based on the subjects previous experience, most reading activities are heavily guided by the teacher, without allowing sufficient space for the students to respond to the text independently. Usually the teacher will guide the students on how to think about the text and give intructions on how to do the reading assessment afterwards. That is why, at the first week of treatment, 
some of the subjects found difficulty in giving comments to the text because they are not used to come up with their own thoughts. In the same way, the subjects experienced difficulties in making inferences so the teacher had to give oral prompting questions all along the treatment in order to help activate the subjects' schemata. These prompting questions are in line with the suggestion of Haidar \& Al Naqabi (2008) in using more divergent questions such as evaluative and reflective questions.

By using metacognitive strategies, subjects are trained to think independently and try to comprehend the text by themselves. If the subjects do not comprehend the text, then it would be impossible for them to give relevant comment on the comment column. Therefore this strategy conditions the subjects to comprehend the meaning of a paragraph before moving on to the next paragraph. Sometimes the subjects commented that thay do not know what to say in the comment column mostly because their mind is not trained to repsond to the text actively.

After weeks of treatment where the subjects had to make active responses to the text, the post test result shows significant improvement in their reading comprehension skill. This is in line with the statement of Sheorey and Mokhtari (2001); being "active and contructively responsive readers" will enhance the readers' reading comprehension. The reason behind this improvement is because the subjects correlated the reading text with their activated schemata thus improving their comprehension about how they can relate to the text (Kostons \& Van der Werf , 2015), (Collins \& Smith, 2008). They also need to stop, think and react to each paragraph. This stop, think and react procedure will make sure the readers understand every part of the passage and the researcher can examine the subjects' comprehension on every paragraph.

The subjects were also encouraged to utilize the six steps of metacognitive strategy whenever they read. As what Nicolielo-Carrilho \& Hage (2017) claimed, better utilization of reading strategies leads to better textual comprehension. Hopefully, by doing so, in the long term subjects can be self regulated learners where they do not always acquire teachers' help in comprehending the text. (Paris and Winograd, 1990).

\section{Conclusions}

Based on the data analysis and discussion in the previous chapter, there are several conclusions that can be drawn from this research. First, the mean score of each pair increases after the treatment which means the subjects have a good potential to implement metacognitive strategy as long as they are given the right directions. However, researcher had to give a lot of guidance in the form of prompting questions throughout the treatment. If this were conducted in the long term, supposedly the guidance could be gradually decreased and the subjects would be able to do the strategy more independently.
Since the significance of this strategy is shown through the result, we can say that the six steps proposed by Brown, Palinscar and Armbruster's (1984) is effective in enhancing the subjects' comprehension. It encourages the readers to ponder upon what they are reading and to give reaction, such as comments or drawings. This will help young learners to be more aware of their comprehension and not just skim through the text but fully comprehend what they are reading.

.All in all, metacognitive strategy is very crucial to develop young learners' way of thinking. It will help them to draw conclusion 
from the lessons they experience thus enabling them to enhance their own knowledge. In the long run, hopefully learners will be able to make "wise and thoughtful life decisions" as Flavel (1979, p. 910) has stated. So that they will not only be able to perform better academically, but also able to achieve their life goals beyong the academic walls.

\section{Suggestions}

Based on the finding of this research, there are several suggesstions which might be benefitial for academic practitioners or non academic alike. Below are the suggestions that this research could be beneficial to:

\section{Curriculum Designers}

Curriculum designers, especially who work in the curriculum department of the school where this research was conducted, need to consider the length of duration for each lesson in relation to the students' mastery level.

If a certain material is not yet fully comprehended by most students then the next objective should be put on hold. The quality of comprehension, instead of the quantity of the materials, should be the first priority in designing curriculum. Especially if metacognitive strategy is going to be implemented, it will take rather longer duration to teach the strategy than the regular lesson hours. In the end, if we aim for quality, we have to sacrifice the quantity. The more material covered is not always the better. The better curriculum is when most students have in depth understanding of what being taught and are able to monitor their development.

\section{Teachers}

Implementing metacognitive strategy in reading may be relatively hard and require a lot of work as well as longer teaching sessions in the beginning. Yet in the long term, it will be very benefitial for the teacher since the main objective of implementing this strategy is to create self regulated learners. Teachers will only act as facilitators during reading sessions and students will be able to monitor their own reading progress. It will be possible if teachers are willing to try this strategy, implement the steps in every reading session, then sooner or later, the desired result should be achieved.

\section{Students}

Students who implement this strategy are encouraged to be more actively involved in the reading session. They are encouraged to speak out their voice which might remain hidden during usual reading session. Thinking aloud is very benefitial for students in a way that it promotes higher order thinking skill. Students are conditioned to activate their background knowledge and to relate the text with their schema, thus analyzing the text. Students should know this benefit if they want to consistently train their metacognitive strategy in reading. It is not just about merely improving their English reading scores, it is about improving the way they see their problems in life and how they respond to it.

\section{Government}

In establishing the National Curriculum, The Government should take a more studentcentered approach rather than teacher centered. Metacognitive strategy is a very suitable option in terms of student centered approach. Not only that, this strategy should be implemented since very early phase of education which is preschool. If metacognitive strategy is taught in higher grades than it will be harder for educators to change the mindset of the students. It will be even better if the government employs metacog- 
nitive strategy throughout the curriculum of other subjects, not only English language. This thorough implementation will enhance the speed of students' metacognitive development.

\section{Future Research}

Metacognitive strategy is still relatively new among educators in Surabaya. Therefore this topic has a great potential to be a research topic, especially when conducted among young learners. Since most of the reasearches available online are conducted among adult learners. Future researchers might also conduct this research with different participants from higher or lower grade. Researchers may also invent and try out new treatment based on the same theory. Not only in reading subject, research on metacognitive strategies can also be implemented in other subjects such as Mathematics, Science,etc.

\section{(C) Diana Tandean}

Diana Tandean is a Character Building Coordinator and Global Perspective teacher at Mawar Sharon Christian School. She obtained her Bachelor's degree in Architecture from Petra Christian University and Master's degree in English Education from Widya Mandala Surabaya Catholic University. She's been interested in educational psychology, specifically, metacognition among young children and its implementation in reading lessons.

\section{References}

Larkin, S. (2010). Metacognition in Young Children. Oxon: Routledge.

Nelson, T. O., \& Narens, L. (1990). Metamemory: A Theoretical Framework and New Findings. The Psychology of Learning and Motivation.

Phillips, S. (1993). Primary students. Oxford University Press.

Creswell, J. W. (2012). Collecting qualitative data. Educational Research: Planning, Conducting, and Evaluating Quantitative and Qualitative Research. Fourth ed. Boston: Pearson, 204-35.

Dutcher, P. (1990). Authentic reading assessment. ERIC Digest (ED328607). Clearinghouse on Tests, Measurement, and Evaluation, Washington, DC; American Institutes for Research, Washington, DC.

Flavell, J. (1979). Metacognition and Cognitive Monitoring: A New Area of Cognitive - Developmental Inquiry. American Psychologist Vol.24, No.10, 906-911
Haidar, A. H., \& Al Naqabi, A. K. (2008). Emiratii High School Students' Understandings of Stoichiometry and the Influence of Metacognition on Their Understanding. Research In Science \& Technological Education, 26(2), 215237.

Hartman, H.J. (2001b). Teaching metacognitively. In H.J. Hartman (Ed.), Metacognition in learning and instruction: Theory, research and practice (pp. 149172). Boston: Kluwer Academic.

Kistner, S., Rakoczy, K., Otto, B., Dignathvan Ewijk, C., Buttner, G., \&Klieme, E. (2010). Promotion of self-regulated learning in classrooms: Investigating frequency, quality, and consequences for student performance. Metacognition and Learning, 5(2), 157-171.

Maasum, T. N. R. T. M., \& Maarof, N. (2012). Empowering ESL readers with metacognitive reading strategies. PrOcedia-Social and Behavioral Sciences, 69, 1250-1258. 
Mokhtari, K., \& Sheorey, R. (2002). Measuring ESL students' awareness of reading strategies. Journal of developmental education, 25(3), 2-11. Barnett, M. A. (1989). Reading as a process. The French Review, 63(1), 31-44

Nash-Ditzel, S. (2010). Metacognitive reading strategies can improve self-regulation. Journal of College Reading and Learning, 40(2), 45-63.

Nicolielo-Carrilho, A. P., \& Hage, S. R. D. V. (2017). Metacognitive Reading Strategies of Children with Learning Disabilities. In Codas (Vol. 29, No. 3). Sociedade Brasileira de Fonoaudiologia.

Scharlach, T. (2008). START Comprehend- ing: Students and Teachers Actively Reading Text. Reading Teacher, 62(1), 20-31.

Sheorey, R., \& Mokhtari, K. (2001). Differences in the Metacognitive Aware-ness of Reading Strategies among Native and Non-Native Readers. System, 29(4), 431-449.

Woolley, G. (2011). Reading comprehension. In Reading Comprehension (pp. 15-34). Springer, Dordrecht.

Zhussupova, R., \& Kazbekova, M. (2016). Metacognitive strategies as points in teaching reading comprehension. Procedia-Social and Behavioral Sciences, 228, 593-600. 